\title{
Scleral and choroidal calcifications in a patient with pseudohypoparathyroidism
}

\author{
SUSAN WONG, Z. NICHOLAS ZAKOV, AND DANIEL M. ALBERT \\ From the Howe Laboratory of Ophthalmology, Massachusetts Eye and Ear Infirmary, Boston, \\ Massachusetts, USA
}

SUMMARY This case report suggests that calcifications in the sclera and choroid may be a feature of pseudohypoparathyroidism and shows a calcium distribution more extensive and severe than that characteristically seen in other metabolic conditions associated with calcium deposits in the eye. Ocular ectopic calcification is a part of the more generalised ectopic soft tissue calcification seen with pseudohypoparathyroidism. Evaluation of the contribution of the terminal renal failure and uraemia to the ectopic ocular calcification would require sequential evaluation of eyes with pseudohypoparathyroidism, but without the added complication of uraemia.

Calcification of the sclera and the choroid associated with pseudohypoparathroidism has not been previously reported. This paper describes a patient in whom this condition apparently contributed to such calcification. Other causes of calcification in the sclera and choroid are reviewed.

\section{Case report}

Our patient was a white female dietary worker who died in 1977 at 29 years of age from complications of pseudohypoparathyroidism. She was diagnosed to have this disorder at the Massachusetts General Hospital in 1956 at the age of 9 years. Pseudohypoparathyroidism was initially suspected because of the characteristic habitus of truncal obesity, round facies, shortening of the fourth metatarsals, recurrent subcutaneous calcifications in the extremities, mental retardation with an IQ of 67 , and biochemical abnormalities of hypocalcaemia $(7.2 \mathrm{mg} / 100 \mathrm{ml}(1.8 \mathrm{mmol} / \mathrm{l})$; normal 9.0 to $11.5 \mathrm{mg} / 100 \mathrm{ml}(2.25$ to $2.87 \mathrm{mmol} / \mathrm{l}))$, and hyperphosphataemia $(9.7 \mathrm{mg} / 100 \mathrm{ml}(3.13 \mathrm{mmol} / \mathrm{l})$; normal 3.0 to $4.5 \mathrm{mg} / 100 \mathrm{ml}(0.97$ to $1.45 \mathrm{mmol} / \mathrm{l}))$. No eye abnormalities were noted on examination at that time. At the time of her diagnosis the patient was begun on supplemental vitamin D of 50000 units per day. While she was on this regimen her serum calcium levels were found to be in the range of 8 to $10 \mathrm{mg} / 100 \mathrm{ml}$ ( 2 to $2.5 \mathrm{mmol} / \mathrm{l}$ ), while her

Address for reprints: Dr Daniel M. Albert, Howe Laboratory, Massachusetts Eye and Ear Infirmary, 243 Charles Street, Boston, Massachusetts 02114, USA serum phosphate levels were reported in the range of 6.8 to $9.5 \mathrm{mg} / 100 \mathrm{ml}(2.20$ to $3.07 \mathrm{mmol} / \mathrm{l})$.

The vitamin D therapy was discontinued in 1963 . The patient did well for 2 years, but in 1965, at the age of 17, she developed grand mal seizures. The results of hospital studies carried out at that time revealed a serum calcium level of $5.6 \mathrm{mg} / 100 \mathrm{ml}$ $(1.4 \mathrm{mmol} / \mathrm{l})$, a skull $x$-ray indicating calcification in the caudate nuclei, and an electroencephalogram (EEG) suggestive of 'structural brain disease'. Her seizures were attributed to her hypocalcaemic state, and vitamin D was administered at a dose of 100000 units per day. In addition she was given supplemental calcium (calcium chloride $30 \%$ in $5-\mathrm{ml}$ doses by mouth 3 times a day) and phenytoin sodium $100 \mathrm{mg}$ by mouth twice a day.

In 1968, while maintained on 100000 units of vitamin D per day, the patient developed symptoms which were suggestive of vitamin $\mathbf{D}$ intoxication. She had bleeding from the upper gastrointestinal tract and a serum calcium of $13.5 \mathrm{mg} / 100 \mathrm{ml}$ (3.37 mmol/1). Her vitamin D was discontinued, and her serum calcium levels declined to normal limits. At that point vitamin $\mathrm{D}$ therapy was begun at a reduced dose of 50000 units per day. During her hypercalcaemic state the patient complained of ocular discomfort. Eye examination at that time showed conjunctivitis, but no other abnormalities were found.

After this episode of vitamin D intoxication there were no recurrences of hypercalcaemia attributable to that therapy. However, from 1968 the patient began to show signs of progressive renal impairment with rising values of BUN and creatinine. Between 


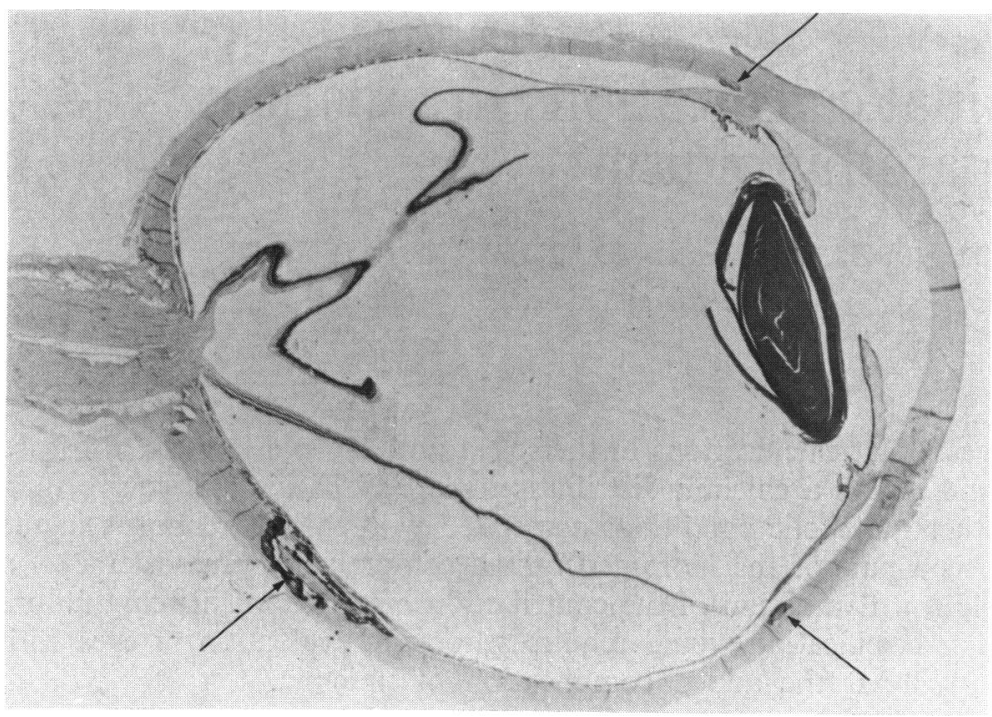

Fig. 1 Low-power section of the globe showing areas of scleral and choroidal calcification (arrows). ( $H$ and $E, \times 6.4)$

Fig. 2 Higher power showing details of calcification of Fig. 1 with extensive scleral and choroidal calcification with sparing of the retinal pigment epithelium. ( $H$ and $E, \times 64)$

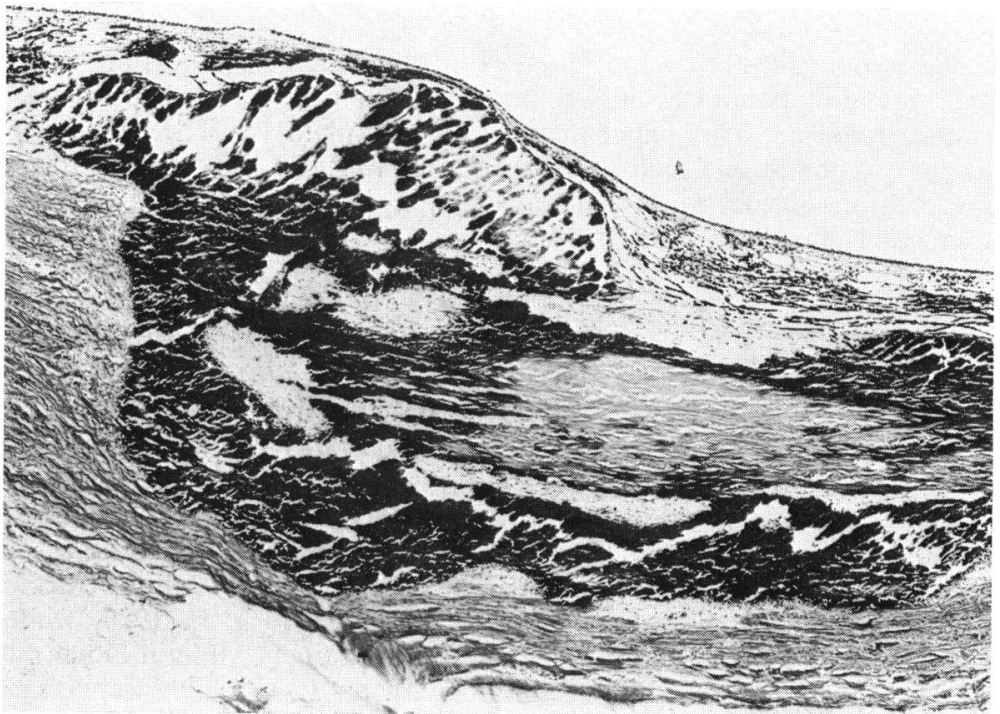

1976 and 1977 she required many admissions to the hospital owing to the development of chronic renal failure with progressive uraemia. Calcium levels ranged from 7.6 to $9.1 \mathrm{mg} / 100 \mathrm{ml}(1.9$ to $2.27 \mathrm{mmol} / \mathrm{l})$, and phosphorus from 4.1 to $7.9 \mathrm{mg} /$ $100 \mathrm{ml}(1.32$ to $2.55 \mathrm{mmol} / \mathrm{l})$.

Before her death she developed secondary hypertension, hypertensive encephalopathy, anuria, ascites, and secondary pancreatitis. She died on 25 April 1977 as a result of renal failure, bronchopneumonia, and pulmonary oedema.

The findings at necropsy included (1) metastatic calcifications of subcutaneous tissues, pancreas, and basal ganglia of the brain; (2) bilateral renal atrophy with uraemic changes; (3) pulmonary oedema, pulmonary effusions, and acute bronchopneumonia; (4) cardiomegaly and fibrinous pericarditis; and (5) skeletal abnormalities.

Lesions present in both eyes included (1) bullous keratopathy; (2) cataractous lens changes; (3) serous retinal detachment; and (4) bilateral scleral and choroidal calcifications (Fig. 1), confirmed by von Kossa and alizarin red stains. The calcium deposits involved almost the entire thickness of the sclera in multiple areas and replaced and compressed the overlying choroid. There was no calcification at the level of the retinal pigment epithelium or neural retina (Fig. 2). 


\section{Discussion}

Pseudohypoparathyroidism is a hereditary disorder initially described by Albright in 1942. It shares with hypoparathyroidism the metabolic abnormalities of hypocalcaemia, hyperphosphataemia, and decreased urinary phosphate excretion, with attendant signs of tetany or convulsions. However, it differs from hypoparathyroidism by the absence of response to normally produced parathyroid hormone, presumably owing to a renal end-organ defect. Patients with this condition have a characteristic habitus with round face, short stature, stocky build, and short metacarpals and metatarsals. Mental retardation, hypocalcaemic cataracts, and blurred disc margins may also be present. Ectopic soft tissue calcification is a prominent part of the syndrome. These ectopic calcifications have been reported in the basal ganglia, the lens, and the subcutaneous tissues, but description of scleral and choroidal calcifications in patients with pseudohypoparathyroidism could not be found on careful review of the literature.

Multiple disease entities are associated with ocular calcification. This can occur after inflammatory, infectious, and traumatic injuries to the eye in which there are significant secondary tissue atrophy, degeneration, and necrosis as occurs in phthisis bulbi. From the detailed history available and the histopathological findings there is no evidence of previous injury to this patient's eyes which can account for the scleral calcifications found at the time of necropsy. Ocular calcification has been reported in hyperparathyroidism (Cogan et al., 1948; Walsh and Murray, 1953; Jensen, 1975), in acute and chronic renal failure (Berlyne and Shaw, 1967), in sarcoidosis (Cogan et al., 1948; Walsh and Murray, 1953; Crick et al., 1961), in vitamin D intoxication (Howard and Meyer, 1948; Walsh and Murray, 1953; Gifford and Maguire, 1954; Leira, 1954), and in hypercalcaemia with band keratopathy (Leira, 1954). All these entities involve an imbalance of the serum calcium and phosphate levels. The presentation and the location of the calcium deposits in these diseases usually differ from the findings in our patient. In hyperparathyroidism Berkow et al. (1968) reported the sites of these calcifications to be the nuclei of the basal layer of the corneal epithelium, stromal keratocytes, and the nuclei of the endothelial cells of the cornea. In the hypercalcaemic state the calcium deposits found in band keratopathy are characteristically located in the Bowman's membrane in the form of spherules (Berkow et al., 1968). The medical findings in our patient rule out hyperparathyroidism and sarcoidosis as causes of her scleral calcifications. Limbal scleral calcifications of a mild degree and senile scleral plaques in the area of insertion of the extraocular muscles are occasionally observed on pathological examination of eyes at necropsy. Our patient's young age and the severity of calcification observed are not consistent with ageing changes as an explanation for her calcifications.

In vitamin $D$ intoxication metastatic calcifications of the cornea and conjunctiva have been reported (Walsh and Murray, 1953). These calcium deposits are reversible after the serum calcium level is corrected to normal levels (Wash and Murray, 1953). Our patient developed vitamin D intoxication with transient hypercalcaemia 9 years before her death. However, her calcium levels subsequently were within normal limits or lower than normal, and no recurrence of the hypercalcaemia was noted in subsequent years. We consider it highly unlikely that the severe scleral calcifications seen histopathologically could be attributed to the vitamin D intoxication which occurred 9 years earlier.

With the biochemical abnormalities of the hypocalcaemia and hyperphosphataemia in pseudohypoparathyroidism are characteristically found ectopic calcifications in the basal ganglia, the subcutaneous tissues, and the lens (Potts, 1972). By the same process it is likely that ectopic calcifications could develop in the sclera and choroid of patients with pseudohypoparathyroidism. We postulate that the biochemical imbalance of calcium and phosphate resulting from the defective response of the endorgans for the parathormone contributed principally to the formation of these ectopic calcifications in the basal ganglia and subcutaneous tissue as well as the sclera and choroid.

Our patient also had chronic renal failure with the development of progressive uraemia in the last 8 years of her life. In chronic renal failure eye calcifications have been reported in the conjunctiva, cornea, and the sclera (Potts, 1972; Porter and Crombie, 1973; Demco et al., 1974; Harris et al., 1971). Given this patient's renal condition at the time of her death, it is certainly possible that her compromised renal status may also have been a factor in the scleral calcium deposition. In our experience and from published reports the degree of calcification found in our patient's sclera and choroid would appear to be unusual for terminal renal failure alone. To determine the relative contribution of the renal failure and the pseudohypoparathyroid state to the ocular calcification we would suggest that radiological studies including a computerised axial tomography scan or B-mode ultrasonography, or perhaps scleral biopsies should be considered early in the course of other patients with this disease. Since renal failure is not a constant 
complication of pseudohypoparathyroidism, this should be possible in some patients.

\section{References}

Albright, F., Burnett, C. H., Smith, P. H., and Parson, W. (1942). Pseudo-hypoparathyroidism-example of 'Seabright-bantam syndrome': report of 3 cases. Endocrinology, 30, 922-932.

Berkow, J. W., Fine, B. S., and Zimmerman, L. E. (1968). Unusual ocular calcifications in hyperparathyroidism. American Journal of Ophthalmology, 66, 812-824.

Berlyne, G. M., and Shaw, A. E. (1967). Red eyes in renal failure. Lancet, 1, 4-7.

Cogan, D. B., Albright, F., and Bartter, F. C. (1948). Hypercalcemia and band keratopathy. Archives of Ophthalmology, 40, 624-638.

Crick, R. P., Hoyle, C., and Smellie, H. (1961). The eyes in sarcoidosis. British Journal of Ophthalmology, 45, 461-481.

Demco, T. A., McCormick, A. Q., and Richards, J. S. F. (1974). Conjunctival and corneal changes in chronic renal failure. Canadian Journal of Ophthalmology, 9, 208-213.
Gifford, E. S., Jr., and Maguire, E. F. (1954). Band keratopathy in vitamin D intoxication. Archives of Ophthalmology, 52, 106-107.

Harris, L. S., Cohn, K., Toyofudu, H., Lonergan, E., and Galin, M. A. (1971). Conjunctival and corneal calcific deposits in uremic patients. American Journal of Ophthalmology, 72, 130-133.

Howard, J. E., and Meyer, R. J. (1948). Intoxication with vitamin D. Journal of Clinical Endocrinology, 8, 895-910.

Jensen, O. A. (1975). Ocular calcifications in primary hyperparathyroidism. Acta Ophthalmologica, 53, 173-186. Leira, H. (1954). Hypercalcemia and band keratopathy. Acta Ophthalmologica, 32, 605-607.

Porter, R., and Crombie, A. L. (1973). Corneal and conjunctival calcification in chronic renal failure. British Journal of Ophthalmology, 57, 339-343.

Potts, J. T. (1972). Pseudohypoparathyroidism. In The Metabolic Basis of Inherited Disease, 3rd edn., pp. 13051319. Edited by J. B. Stanbury, J. B. Wyngaarden, and D. W. Frederickson. McGraw-Hill: New York.

Walsh, F. B., and Murray, R. B. (1953). Ocular manifestations of disturbances in calcium metabolism. American Journal of Ophthalmology, 36, 1657-1676. 